Case Report

\title{
A rare case report of Sandoff disease presented as neuroregression disorder
}

\author{
Phuljhele S. ${ }^{1}$ Rathi $Y^{2}$ \\ ${ }^{1}$ Dr. Sharja Phuljhele, Professor, HOD, ${ }^{2}$ Dr. Yogita Rathi, PG Resident; both authors are affiliated with Department of \\ Paediatrics, Pt. J.N.M. Medical College, Raipur (CG)
}

Corresponding Author: Dr. Yogita Rathi, PG Resident of Department of Paediatrics, Pt. J.N.M. Medical College, Raipur, Chhattisgarh. Email: rathiyogita1410@gmail.com

\begin{abstract}
Sandhoff disease is a rare lysosomal storage disorder which is inherited in an autosomal recessive pattern. The prevalence of the disease is 1 in 384000 live births. Here the present case report of 14 month old male child who was presented with macrocephaly, regression of developmental milestones and seizures. Fundus examination showed macular cherry red spot. Enzyme studies revealed reduced levels of beta hexosaminidase A and B, following which a diagnosis of Sandhoff disease was made. Fundus examination showed macular cherry red spot. Mother was offered prenatal diagnosis of the fetus in the subsequent pregnancy, which was also found to have the same enzyme deficiency and the pregnancy was medically terminated. Early identification of this neurodegenerative disorder, helped in preventing the birth of subsequent affected children in the same family, thereby reducing the burden on the family as well as the society.
\end{abstract}

Keywords: $\beta$-hexosaminidase A and B, Cherry red spot, Optic atrophy, Sandhoff disease

\section{Introduction}

Sandhoff disease is a lysosomal storage disorder. The mode of inheritance is autosomal recessive. Prevalence of Sandhoff disease is 1 in 384000 live births [1]. The Sandhoff carrier frequency in non-Jewish population (36 in 10000) is higher than the Jewish population (20 in 10000). There are more than 30 diverse groups of lysosomal storage disorders; one among them is GM2 gangliosidoses. This group includes only two diseases, Taysach and Sandhoff disease.

They result from the deficiency of $\beta$-hexosaminidase activity and the lysosomal accumulation of GM2 gangliosides, particularly in the central nervous system [2]. Sandhoff disease represents $7 \%$ of GM2 gangliosidoses [3]. Since only b-hexosaminidase A is able to degrade GM2 ganglioside, the substrate accumulates similarly in each disease. Affected individuals with either disease exhibit a virtually identical clinical course of neurodegeneration leading to death in early childhood. Apoptosis of neurons is demonstrable in-patient samples and in mouse models $[4,5]$. While it is clear that a primary insult to neurons is the accumulation of ganglioside substrates, the exact molecular mechanisms that translate the primary insult into neuronal cell death remain to be determined. One alluring approach to gain insight into pathophysiology is to generate gene expression profiles of the central nervous system (CNS) in patients affected with these disorders [6]. Such profiles would reveal how gene expression in the diseased state differed from that of the normal. Subsequent scrutiny of those genes exhibiting altered expression could be a wellspring for hypotheses regarding the pathways leading to the observed neurodegeneration. Advances, including serial analysis of gene expression (SAGE) [7]. Here we report one such rare case of Sandhoff disease. The 'cherry-red spot' is the hallmark of GM Gangliosidase Deficiency. It is the result of GM2 accumulation in the retinal ganglion cells, giving the white fundus appearance surrounding the normal tint of the fovea. The diagnosis was confirmed by molecular genetic testing [8].

\section{Case Report}

A 14-month-old girl was brought to the hospital by his parents for seizures. she presented with a history of neuro regression since 6 months old and seizures 15 days back at age of $14^{\text {th }}$ month. He was born full-term at 38 weeks with history of not cried

Manuscript received: $10^{\text {th }}$ October 2019

Reviewed: $20^{\text {th }}$ October 2019

Author Corrected: $26^{\text {th }}$ October 2019

Accepted for Publication: $30^{\text {th }}$ October 2019 
Case Report

after birth for 10 mins (ambulance delivery) but there was no NICU stay. The patient was developing normally until she was 6 months old when it was observed that the child was listless and lost the ability to move his limbs, neck holding and roll over. Since then, the loss of motor skills became progressively evident. The patient is the third child of a healthy nonconsanguineous couple. There were no similar manifestations in both parents' families. Clinically, she was a thriving child, with coarse facies. she had quadriplegia, decreased eye contact.

On examination at 14 month of age, the patient's occipitofrontal circumference $(44 \mathrm{~cm})$, height $(75 \mathrm{~cm})$ and weight $(7.5 \mathrm{~kg})$ were around average. There were coarse facies present. she had feeding difficulties. Her tendon reflexes brisk at the knees and ankle and he had normotonia with right sided lower motor neuron $7^{\text {th }}$ cranial nerve palsy. On per abdomen examination hepatomegaly was of $3-4 \mathrm{~cm}$ from right costal margin. Cardiovascular and the remainder of his examination were unremarkable.

Ophthalmic assessment confirmed severe visual impairment and fundoscopic examination revealed bilateral retinal 'cherry-red spots' (Figure 1).

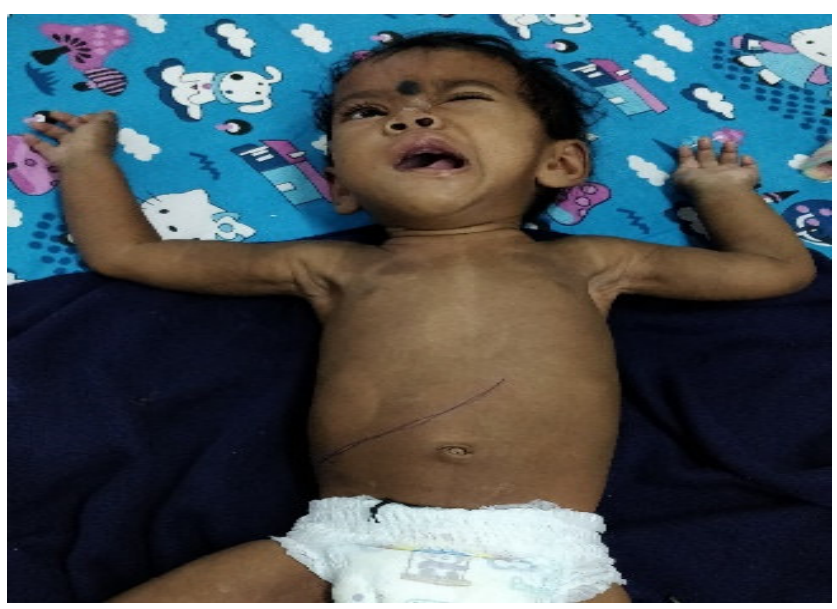

Fig-1: Macrocephaly, vacant stare with facial palsy and hepatomegaly.

Anterior segment examination of both eyes were insignificant. Clinical presentation associated with corroborative fundoscopic findings geared the diagnostic workup towards lysosomal storage disorders, in particular neurolipidoses.

Neuroimaging (MRI brain) revealed leukodystrophic changes (T1 hyperintensity, T2 hypointensity noted involving bilateral thalamus, splenium of corpus callosum and diffuse hyperintensity noted involving white matter of bilateral cerebral hemisphere) (Figure 2 and Figure 3).

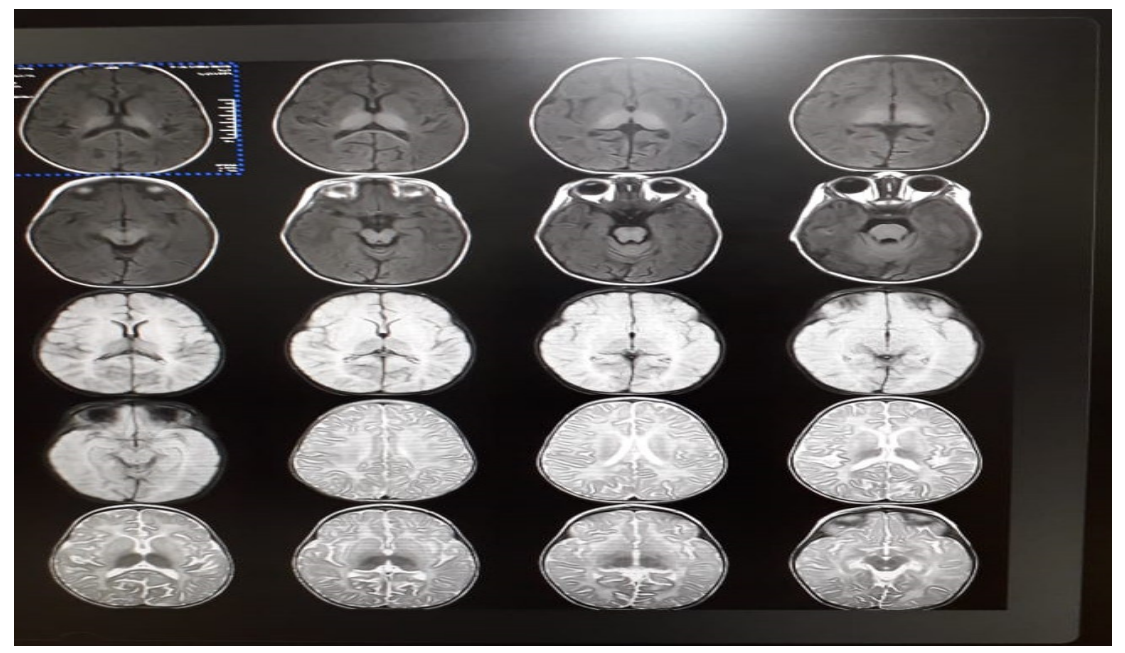

Fig-2: Leukodystrophic changes observed upon MRI. 
Case Report

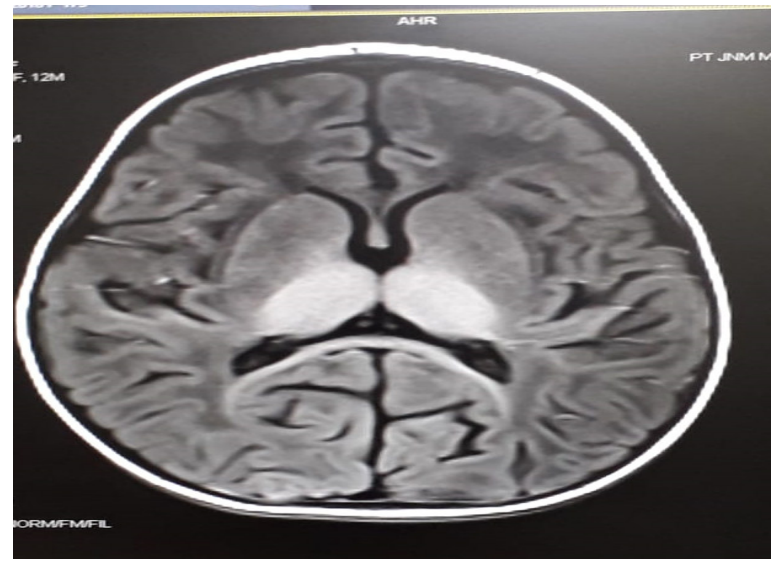

Fig-3: Neuroimaging (MRI brain) revealed leukodystrophic changes.

Enzyme studies- With macrocephaly, regression of milestones and cherry red spot, Taysach's disease and Sandhoff disease were considered and enzyme studies were sent (Figure 4).

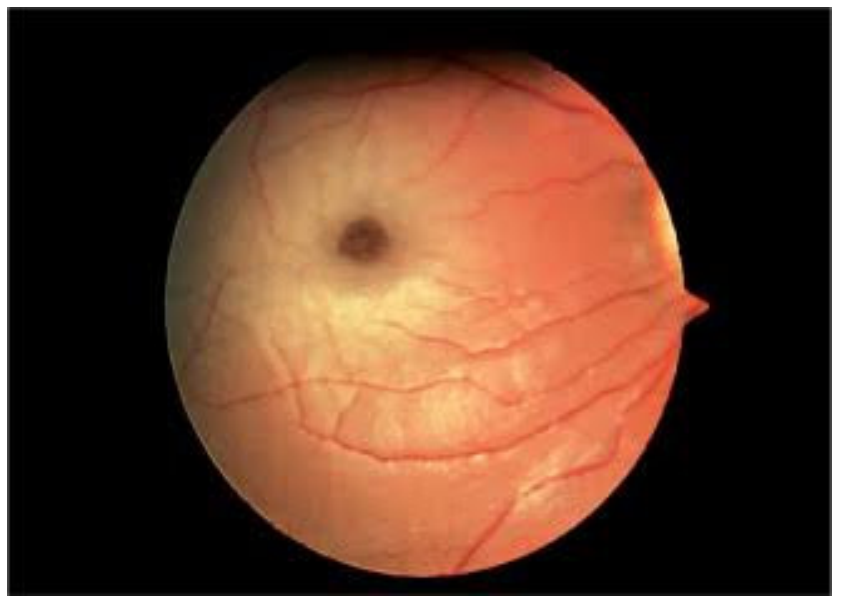

Fig-4: Cherry red spot changes.

Enzyme levels in the present case were as follows:

Beta hexosaminidase A and B: $140.95 \mathrm{nmol} / \mathrm{hr} / \mathrm{mg}(\mathrm{N}:>1150 \mathrm{nmol} / \mathrm{hour} / \mathrm{mg})$ suggesting Sandhoff disease. Genetic counseling and options of prenatal diagnosis in subsequent pregnancies were provided to the parents. The parents were also counseled regarding appropriate health care for their son and probable outcome which is death occurring by age 4 or 5 years. The patient is still under clinical observation by the ophthalmology and genetic teams.

GM1 gangliosidoses are characterized by deficient levels of beta galactosidase with neuroimaging findings similar to GM2 gangliosidoses. This is because both GM1 and GM2 gangliosides structurally differ only in the terminal N-acetyl galactosamine. They are identified by specific enzyme assay [9]. Our case had bilateral thalamic involvement with cherry red spot in $\mathrm{b} / 1$ macula suggestive of tay-sachs disease.

\section{Discussion}

Sandhoff disease is a lysosomal storage disorder. The disease is named after Konrad Sandhoff, a German chemist. It is characterised by exaggerated startle reaction, regression of milestones, hepatosplenomegaly, skeletal dysplasia, cherry red spot and seizures. The early symptoms of hypotonia and acoustic hypersensitivity are followed by spasticity and hearing loss. Seizures are usually a late manifestation of the disease. It is estimated that early seizures indicate severity of the disease and are associated with poor developmental outcomes. 4 There is no correlation between the severity of neuroimaging and clinical picture [8]. The gene that causes Sandhoff is located on chromosome 5 , specifically $5 \mathrm{q} 13$. It is called HEX B gene. This gene provides instructions for making a 
Case Report

protein that is part of two critical enzymes in the nervous system, beta hexosaminidase A and beta-hexosaminidase B. These enzymes are located in lysosomes. Mutations in the gene lead to reduced enzyme levels, such that GM2 gangliosides accumulate in the neurons of brain and spinal cord producing the symptoms [9].

pe based on the age of onset and clinical features. The most common type is the infantile form. Here the child is normal at birth, with disease onset between 3-9 months of age. The disease course is severe leading to death before 3 years of age. Juvenile and adult onset Sandhoff disease are very rare. Children with juvenile Sandoff, do not exhibit the telltale sign of cherry red spot which can make the diagnosis challenging.

Definitive diagnosis is by determination of the deficient levels of the enzyme. A diagnostic neuroimaging marker of Sandhoff disease is bilateral thalamic involvement [3]. A recent advanced diagnostic modality for this disease is proton Magnetic Resonance Spectrography (MRS) of the cerebral metabolites. Wilken et al. in their study identified increased levels of inositol (glial marker) and reduced amount of total $\mathrm{N}$-acetylaspartate which is a neuroaxonal marker in a proved case of Sandhoff disease [9].

Sandhoff disease 'breeds true' in a family. If one child is diagnosed with infantile Sandhoff, then the other children are at risk only for the infantile form. One set of parents cannot have children with both the infantile and juvenile forms of the disease.

Our case falls under the category of infantile type of Sandoff disease with classical clinical presentation and confirmatory enzyme deficiency. clues found on fundus examination 4. It is due to GM2 gangliosides accumulation in the retinal ganglion cells leading to thickening and loss of transparency of the posterior pole of the retina. The absence of ganglion cells at the fovea gives rise to the red spot surrounded by white diseased cells. Its colour is due to the pigment epithelium and choroid, and therefore may demonstrate colour variability according to the race 5. As the ganglion cells die, the 'cherryred spot' fades and optic atrophy becomes apparent. Although experimental work, such as gene therapy research is underway, there is currently no cure or treatment to slow the progression of TSD. Patients receive palliative and supportive care to ease the symptoms [9].

'Cherry-red spot' is a useful clinical indicator in Gangliosidase Deficiency and several other lysosomal storage disorders. A useful sign, when associated with key clinical features and a good history, it often guides one to a diagnosis of the disease. It serves as an ideal illustration of the eye as a window to inborn errors of metabolism.
This case reaffirms that the eyes may offer vital clues in identifying signs of health conditions. We would also like to highlight that an appropriate multidisciplinary approach by the geneticist, ophthalmologist, neurologist and clinical biochemist is crucial in ensuring diagnostic success in various disorders. It is due to GM2 gangliosides accumulation in the retinal ganglion cells leading to thickening and loss of transparency of the posterior pole of the retina.

The absence of ganglion cells at the fovea gives rise to the red spot surrounded by white diseased cells. Its colour is due to the pigment epithelium and choroid, and therefore may demonstrate colour variability according to the race [2].

Both Taysach and Sandhoff have similar clinical presentation with the exception of hepatosplenomegaly and skeletal dysplasia which are absent in Taysach's. Cherry red spot is present in both these conditions. The two conditions are differentiated by the specific enzyme deficiency. Beta hexosaminidase occurs as 2 isoenzymes.

Beta hexosaminidase A is composed of 1alpha and 1beta subunits, whereas beta hexosaminidase B has 2 beta subunits. Mutation in alpha subunit causes deficiency of Beta hexosaminidase A and results in Taysach's disease.

On the other hand, mutation in beta subunit causes deficiency of both beta hexosaminidase A and B and leads to Sandhoff disease [2].

GM1 gangliosidoses are characterized by deficient levels of beta galactosidase with neuroimaging findings similar to GM2 gangliosidoses. This is because both GM1 and GM2 gangliosides structurally differ only in the terminal $\mathrm{N}$-acetyl galactosamine. They are identified by specific enzyme assay [2].

Management- There is no specific treatment for Sandhoff disease. Management is mainly supportive. Research in this area includes gene therapy, substrate inhibitors and pyrimethamine chaperone, which crosses the blood brain barrier and binds with the inactive enzyme so that it takes a correct functional shape. The other research aspects are stem cell therapy, and enzyme replacement therapy. All the above said modalities are in clinical trials [2].

\section{Conclusion}

The prevalence of Sandhoff disease is very rare. Early diagnosis is of progners, knowledge of the $r$ prenatal diagnosis to prevent birth of subsequent affected children.

Funding: No funding sources

Conflict of interest: None 
Case Report

\section{Reference}

1. Sakpichaisakul K, Taeranawich P, Nitiapinyasakul A, Sirisopikun T. Identification of Sandhoff disease in a Thai family: clinical and biochemical characterization. Med J Med Assoc Thailand. 2010;93(9):1088-1092.

2. Robert M. Kliegman, Bonita MD. Stanton, Joseph St. Geme, Nina F. Schor, Richard E. Behrman. Chapter 80 and 592. In: Robert M. Kliegman, Bonita MD. Stanton, Joseph St. Geme, Nina F. Schor, Richard E. Behrman, eds. Nelson Textbook of Paediatrics. 19th ed. USA: Elsevier Publications; 2011: 484,485,2070,2071.

3. Saouab R, Mahi M, Abilkacem R, Boumdin H, Chaouir $\mathrm{S}$, Agader O, et al. A case report of Sandhoff disease. Clin Neuroradiol. 2011;21(2):83-85. doi: 10.1007/s00062-0100035-4. Epub 2010 Dec 10.

4. Ospina LH, Lyons CJ, McCormick AQ. "Cherry-red spot" or "perifoveal white patch"? Canadian J Ophthalmol.2005;40(5):609-610.doi: 10.4103/tjo.tjo_53_17

5. Huang JQ, Trasler JM, Igdoura S, Michaud J, Hanal N, Gravel RA. Apoptotic cell death in mouse models of GM2 gangliosidosis and observations on human Tay-
Sachs and Sandhoff diseases. Hum Mol Genet. 1997;6 (11) : 1879-1885. doi: 10.1093/hmg/6.11.1879.

6. Wada R, Tifft CJ, Proia RL. Microglial activation precedes acute neurodegeneration in Sandhoff disease and is suppressed by bone marrow transplantation. Proc Natl Acad Sci U S A. 2000;97(20):10954-10959. doi: 10.1073/ pnas. 97.20.10954.

7. Caughlin S, Hepburn JD, Park DH1, Jurcic K, Yeung KK, Cechetto DF1, et al. Increased Expression of Simple Ganglioside Species GM2 and GM3 Detected by MALDI Imaging Mass Spectrometry in a Combined Rat Model of A $\beta$ Toxicity and Stroke. PLoS One. 2015;10(6):e0130364. doi: 10.1371/journal.pone.0130364. eCollection 2015.

8. Yüksel A, Yalçınkaya C, Işlak C, Gündüz E, Seven M. Neuroimaging findings of four patients with Sandhoff disease. Pediatr Neurol. 1999;21(2):562-565. doi:https:// doi.org/10. 1007/s00330-005-2846-2.

9. Saouab R, Mahi M, Abilkacem R, Boumdin H, Chaouir $\mathrm{S}$, Agader O, et al. A case report of Sandhoff disease. Clin Neuroradiol. 2011;21(2):83-85. doi: 10.1007/s00062-0100035-4. Epub 2010 Dec 10.

\section{How to cite this article?}

Phuljhele S, Rathi Y. A rare case report of Sandoff disease presented as neuroregression disorder. Int J Pediatr Res.2019;6(11): 577-581.doi:10.17511/ijpr.2019.i11.05 